\title{
Preparation and Release Properties of Sol-Gel Encapsulated Proteins
}

\author{
Yu-Cheng Chen ${ }^{1}$, Ching-Piao Liu ${ }^{2}$, Chun-Kai Yang ${ }^{3}$, Bao-Yu Huang ${ }^{1}$, Chuen-Ying Liu ${ }^{{ }^{*}}$ \\ ${ }^{1}$ Department of Chemistry, National Taiwan University, Taipei, Taiwan; ${ }^{2}$ Department of Food Science/Biological Science and \\ Technology, China University of Science and Technology, Taipei, Taiwan; ${ }^{3}$ Department of Biology, Georgia State University, At- \\ lanta, USA. \\ Email: ${ }^{*}$ cyliu@ntu.edu.tw
}

Received August 15 ${ }^{\text {th }}, 2013$; revised September 15 ${ }^{\text {th }}, 2013$; accepted September $21^{\text {st }}, 2013$

Copyright (C) $2013 \mathrm{Yu}$-Cheng Chen et al. This is an open access article distributed under the Creative Commons Attribution License, which permits unrestricted use, distribution, and reproduction in any medium, provided the original work is properly cited.

\begin{abstract}
A glycoprotein, bovine serum albumin (BSA) was used as a model compound for encapsulation in a sol-gel matrix. Dried gels were ground into powders and meshed to achieve particle sizes less than $250 \mu \mathrm{m}$. The products were washed with phosphate buffer. Capillary electrophoresis was used to evaluate the encapsulation efficiency and the kinetic properties of protein release. Several parameters, including the $\mathrm{pH}$ and composition of the background electrolyte, were investigated in an effort to eliminate the matrix effect from the determination of release kinetics. Complete separation of the silica matrix from BSA was using phosphate buffer, an applied voltage of $15 \mathrm{kV}$, and detection at $278 \mathrm{~nm}$. Kinetic studies indicated that most of the BSA was released in the first $5 \mathrm{~h}$. The rate of BSA release gradually decreased, and some BSA after $25 \mathrm{~h}$. These results indicated that dilute potassium phosphate buffer could accelerate protein release, but this was not observed for the concentrations greater than $50 \mathrm{mM}$. We believe the developed method has potential utility in other systems for in vitro matrix dissolution and drug release studies.
\end{abstract}

Keywords: Bovine Serum Albumin; Capillary Electrophoresis; Encapsulation; Release; Sol-Gel

\section{Introduction}

Therapeutic proteins are becoming available for the treatment of a wide range of diseases. Major limitations to the efficiency of protein therapeutics are reduced stability and short circulation half-lives after parenteral administration [1]. As a result of the invasive nature of these routes of administration, injectable formulations are frequently met with patient discomfort and noncompliance. Additional difficulties for proteins in vivo include susceptibility to proteolysis and colloidal instability. These factors necessitate either high drug concentrations or high dosing frequencies, which may lead to adverse side effects. There is an urgent need for protein delivery systems that will enable targeted, controlled release profiles. Carriers such as liposomes, polymer micelles, and hydrogels have been developed to achieve protein delivery [2].

There has been considerable interest in the use of solgel materials for biological and biomedical applications $[3,4]$. Operating at the interface of biology, chemistry,

\footnotetext{
"Corresponding author.
}

and materials science, this process has been used to immobilize biomolecules via entrapment within sol-gel derived matrices. The interpenetrating networks of silica effectively serve to "cage" the biomolecules, and it remains sufficiently loose to allow for local rotational and translational motions, including those required for substrate binding [5]. Bioencapsulation retains not only the structural integrity of the entrapped biomolecules but also, more importantly, their full biological function [6, 7].

Hydrogels are excellent protein containers [8,9]. However, silica gel encapsulation of living cells and other biological components is not yet understood, due to the complexity of sol-gel chemistry and the variety of materials that may be considered for encapsulation [10].

BSA is a well-studied biomolecule among the wide variety of biological species that have been encapsulated in sol-gel matrices [11-13]. Gao et al. [14] have studied the structural evolution of sol-gel matrices in the presence of BSA. BSA has been encapsulated in a silica matrix to evaluate its utility for the separation of some drug 
enantiomers $[15,16]$. A new type of sol-gel/organic hybrid composite material, using gelatin or chitosan with tetramethyl orthosilicate, was developed to prepare a monolithic column for capillary electrochromatagraphic separation of enantiomers of tryptophan [17].

Calcium silicate is also a potent material for biological and biomedical applications. Fujiwara et al. [18] reported the preparation of calcium silicate microparticles encapsulating proteins by the interfacial reaction method, and their applications to controlled release and drug delivery. Zhao et al. [19] have developed a lower release dual drug delivery system consisting of a calcium phosphate nanocarrier loaded with both BSA and the drug ibuprofen.

Over the last decade, capillary electrophoresis (CE) has achieved as a fast, powerful, efficient, cost effective and high resolution separation technique. Igartua et al. [20] investigated the stability of BSA encapsulated in poly (D,L-lactide-co-glycolide) microspheres using CE. Chen et al. [21] have used CE to determine the concentrations of free and encapsulated oligonucleotides in a liposomal formulaton of a drug product. Nguyen et al. $[22,23]$ reported that they had developed an efficient quantitative CE-ICP-MS method to characterize a liposomal formulation of the anti-cancer agent oxaliplatin. In this work, porous silica particles prepared by the sol-gelprocess were investigated as encapsulation matrices for the controlled release of BSA. This protein release was controlled by careful choice of buffer $\mathrm{pH}$ and buffer concentration. The retention performance of the released BSA was studied by CE. The release kinetic of the encapsulated protein was also subsequently determined.

\section{Experimental}

\subsection{Instrumentation}

All experiments were performed using a laboratory-built unit. The unit consists of $\mathrm{a} \pm 30 \mathrm{kV}$ high voltage power supply (EH 30P3, Glassman, USA) and a UV-Vis detector (870-CE, Jasco, Japan). Electropherograms were recorded and processed with a CT-21 data processor (Peak-ABC, Singapore). The fused silica capillaries (Polymicro Technologies, Phoenix, AZ, USA) had a $75-\mu \mathrm{m}$ i.d. and a $375-\mu \mathrm{m}$ o.d. with a total length of $75 \mathrm{~cm}$ and a distance of $55 \mathrm{~cm}$ between the injection point and the detection window.

\subsection{Reagents and Chemicals}

BSA, disodium 2,2'-biquinoline-4,4'-dicarboxylate ( $\left.\mathrm{Na}_{2} \mathrm{BCA}\right)$ and tetraethyl orthosilicate (TEOS) were obtained from Sigma (St. Louis, MO, USA). Cupric sulfate, sodium carbonate and sodium tartrate were obtained from Acros (Geel, Belgium). Purified water (18 M $\Omega$-cm) from a Milli-Q water purification system (Millipore, Bedford, MA, USA) was used to prepare all solutions.

\subsection{Immobilization of BSA}

TEOS sols were prepared by sonicating a mixture of TEOS $(4.5 \mathrm{~mL})$, pure $\mathrm{H}_{2} \mathrm{O}(1.4 \mathrm{~mL})$ and $0.1 \mathrm{M} \mathrm{HCl}(100$ $\mu \mathrm{L})$ for $1 \mathrm{~h}$ at ambient temperature until it was visibly homogeneous. The sols were stable at $-20^{\circ} \mathrm{C}$ for as long as two weeks. Xerogels were prepared by mixing TEOS sol $(2.4 \mathrm{~mL})$ with $3.9 \mathrm{~mL}$ phosphate buffer $(50 \mathrm{mM}, \mathrm{pH}$ 7) containing $30 \mu \mathrm{g} / \mathrm{mL}$ BSA for protein doped preparations. The mixtures were stored at $4^{\circ} \mathrm{C}$ until gelation occurred. The gels were then ground into fine powders, at which point they were ready for use.

\subsection{Bicinchoninic Acid (BCA) Microassay [24]}

Reagent A was an aqueous solution $(100 \mathrm{~mL}, \mathrm{pH} 11.25)$ of sodium carbonate monohydrate $(0.8 \mathrm{~g})$ and sodium tartrate $(1.6 \mathrm{~g})$. Reagent B was prepared by dissolving BCA $(4 \mathrm{~g})$ in pure water and diluting to the mark (100 $\mathrm{mL})$. Reagent $\mathrm{C}$ was cupric sulfate pentahydrate $(0.4 \mathrm{~g})$ dissolved in water $(10 \mathrm{~mL})$. The assay reagent was prepared to have a volume ratio of reagent $A: B: C$ equal to 26:25:1. Equivalent volume ratios of assay reagent relative to protein standard were prepared and incubated at $60^{\circ} \mathrm{C}$ for $1 \mathrm{~h}$. After cooling to the room temperature, the absorbance was measured at $562 \mathrm{~nm}$ to construct the calibration curve.

Protein release studies were conducted with various sol-gel particles $(30 \mathrm{mg})$. They were immersed in phosphate buffer $(50 \mathrm{mM}, \mathrm{pH} 7.0)$. At predetermined time points, the sample was filtered and the supernatant was injected hydrostatically into the CE system. In each experiment, the sample was analyzed in triplicate.

\subsection{Capillary Electrophoresis}

A fused-silica capillary was flushed prior to use with 0.1 $\mathrm{M} \mathrm{NaOH}$, followed by pure water, for at least $30 \mathrm{~min}$ each. The capillary was then flushed with $0.1 \mathrm{M} \mathrm{HCl}$ for $30 \mathrm{~min}$ followed by pure water for an additional $30 \mathrm{~min}$.

Before analysis, the coated columns were preconditioned with the running buffer. Between sample runs, the columns were rinsed with pure water and running buffer for 1 or $2 \mathrm{~min}$ intervals. The samples were injected by siphoning at a height difference of $20 \mathrm{~cm}$ for $10 \mathrm{~s}$. The samples were monitored at $278 \mathrm{~nm}$ with the UV absorbance detector.

\section{Results and Discussion}

\subsection{BCA Microassay}

We have adopted the method for protein assays because BCA better tolerates the presence of compounds that interfere with the Lowry assay. It is not affected by various detergents and denaturing agents, such as urea and guanidinium chloride, although it is more sensitive to the 
presence of reducing sugars. The calibration curve was prepared over a sample concentration range from $0.4 \mu \mathrm{g} /$ $\mathrm{mL}$ to $20 \mu \mathrm{g} / \mathrm{mL}$. The formula of the calibration curve as derived from the least square method was $y=0.0436 x+$ 0.1613 .

\subsection{Immobilization of BSA}

The sol-gel reaction involves the following steps [25]: 1) hydrolysis of alkoxysilane; 2) condensation of hydrated silica to form siloxane bonds; and 3) polycondensation linkage of additional silanol groups to form cyclic oligomers. Protein molecules are trapped within the silicate network as it forms.

\subsection{Release Rate in Different Buffer Compositions}

The release buffer was similar to the BGE of CE in each case. The rate of protein release from the sol-gel was determined in buffer solutions at different $\mathrm{pH}$ values $(\mathrm{pH} 5$, 7, 8 and 9). Increasing the buffer $\mathrm{pH}$ enhances the electrophoretic mobility of the BSA macromolecule. Greater EOF would also occur at higher $\mathrm{pH}$. The net result revealed a faster migration of the BSA macromolecule (Figure 1). Interestingly, there are two sample peaks which were assigned to be the isoforms of BSA at phosphate buffer concentration of $20 \mathrm{mM}$ and $\mathrm{pH}$ above 5. At buffer $\mathrm{pH} 9$, much greater amount of BSA was released by comparison with those at lower $\mathrm{pH}$ (Figures 1(c) vs. (a) \& (b)). Meanwhile, a slightly different electropherogram from that shown in Figure 1(b) was demonstrated. There are two possible explanations for the phenomena. Either the migration order of the isoforms reversed or the amount of the isoforms altered as the condition changed. Conformational transitions of BSA dependent on $\mathrm{pH}$ and ionic strength might be the reason [11,26-28].

Figure 2 shows the release behavior of BSA encapsulated in the sol-gel. Most of the BSA was released in the first $5 \mathrm{~h}$. A slower release rate was then observed, and some BSA remained encapsulated after $25 \mathrm{~h}$. Gao et al. [29] have investigated the mechanism by which encapsulated BSA is released from polylactic acid-hyperbranched polyglycerol conjugate nanoparticles. The overall mechanism of BSA release from the nanoparticles is heavily dependent on copolymer relaxation, protein diffusion, protein dissolution or combinations thereof. The cumulative BSA release curves exhibited a burst effect followed by a slowly continuous release phase. Similar release behavior (Figure 2) was observed in our own work.

The effect of buffer concentration on the protein release behavior was also investigated. In each case, the buffer concentration was varied over $20,40,50,60,80$ and $100 \mathrm{mM}$ at definite $\mathrm{pH}$ value. The sample peak in-

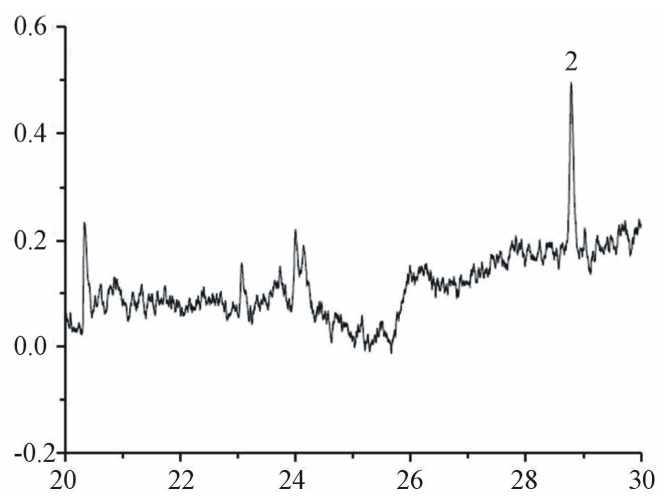

(a)

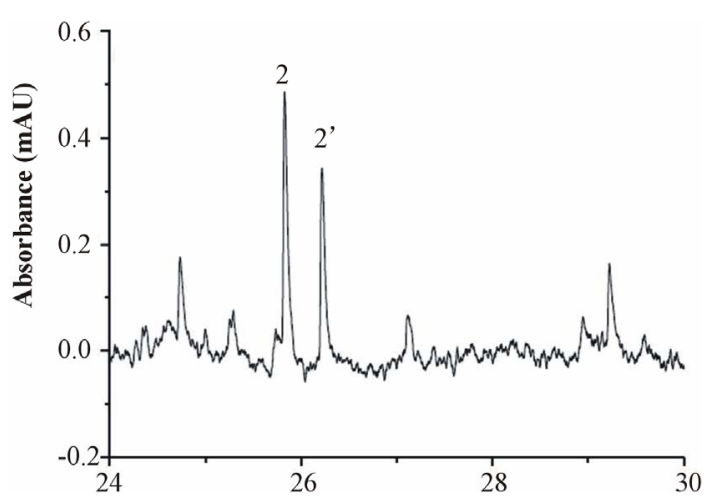

(b)

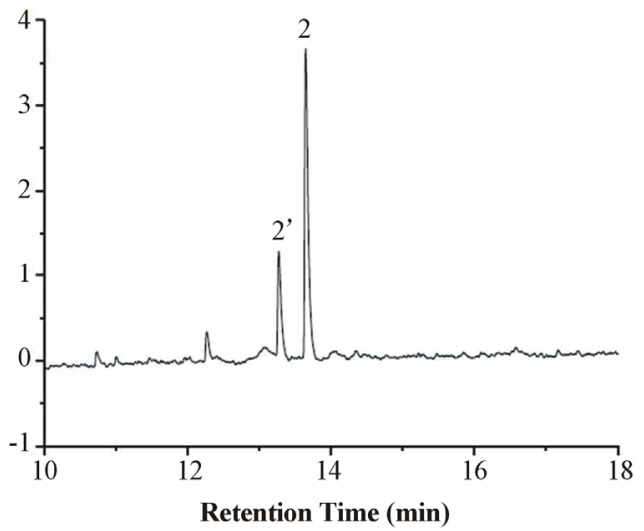

(c)

Figure 1. Electropherograms of BSA released from the sol-gel. Column: $75 \mathrm{~cm}(55 \mathrm{~cm}) \times 75 \mu \mathrm{m}$ I.D.; sample concentration: $1.13 \mathrm{mg} / \mathrm{mL}$; sample injection: hydrostatic $(20$ $\mathrm{cm}, 10 \mathrm{~s})$; applied voltage: $15 \mathrm{kV}$; detection at $278 \mathrm{~nm}$; phosphate buffer (20 mM) (a) pH 5 (b) pH 7 and (c) pH 9. Peaks: 1. sol-gel matrix (not shown in the scale used). 2 and 2' are isoforms of BSA.

tensity increased significantly as the releasing buffer concentration increased. This relationship was not maintained, however, when the buffer concentration was greater than $50 \mathrm{mM}$. A summary (3D plot) of the release profile of the encapsulated protein across various buffer compositions is shown in Figure 3. The peak corresponding to maximum protein release clearly occurs at 


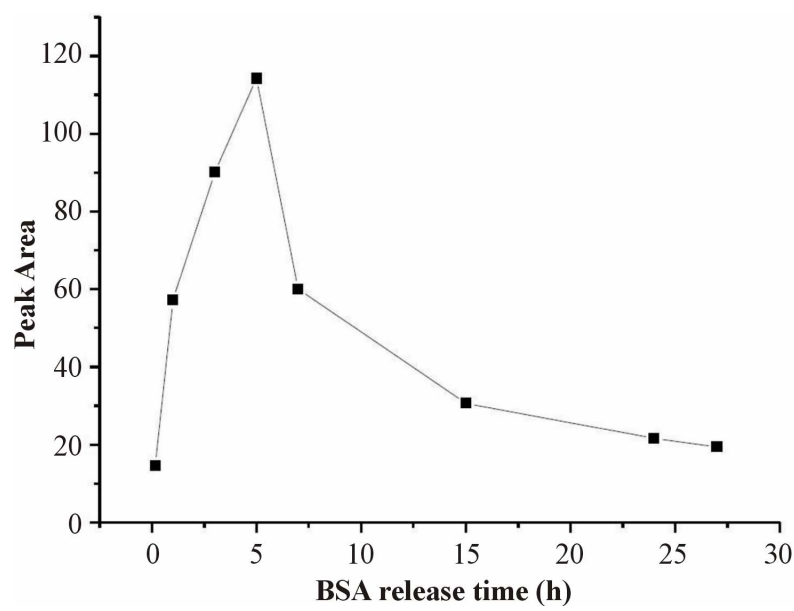

Figure 2. Release rate of the encapsulated protein. Measurement conditions were the same as in Figure 1, except phosphate buffer (50 mM, pH 7).

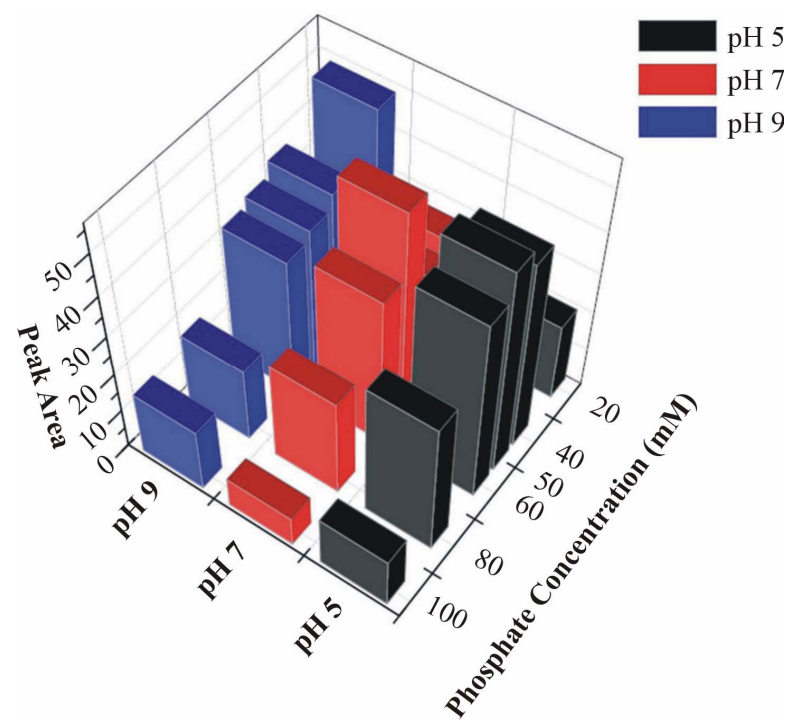

Figure 3. The 3D plot of encapsulated protein released at different compositions of phosphate buffer.

pH 7 with buffer concentrations of approximately 50 $\mathrm{mM}$.

The protein loading capacities of the sol-gel $(1.3 \mathrm{mg})$ were also evaluated. For BSA (1 mL) loadings of 20, 25, 30 and $40 \mu \mathrm{M}$, the amount of protein released after $5 \mathrm{~h}$ immersed in $1 \mathrm{~mL}$ phosphate buffer $(50 \mathrm{mM}$, pH 7) was $54.01 \%, 45.52 \%, 39.92 \%$ and $34.81 \%$, respectively.

\section{Conclusion Remarks}

Most of the drug loading and drug release studies were using spectrophotometric analysis including UV-Vis [18, 19,30,31] and fluorimetry [2] or further combined with LC for the matrix isolation. The delivery of biomolecules has also been studied using confocal microscope image [32]. In this work, only BSA was encapsulated in sol-gels.
Various surface chemistries can be used for modifying the sol-gel structure to achieve longer delivery periods. Other entrapment materials can also be used to tune this property. Here, we proposed a measurement method for kinetic release studies that is simple, fast and consumes lower reagent quantities. We believe the method that we developed has potential utility in other systems for in vitro matrix dissolution and drug release studies.

\section{Acknowledgements}

The authors thank the National Science Council of Taiwan for financial support (Grant No. NSC 96-2113-M002-023-MY3).

\section{REFERENCES}

[1] R. Haag and F. Kratz, "Polymer Therapeutics: Concepts and Applications," Angewandte Chemie, Vol. 45, No. 8, 2006, pp. 1198-1215. http://dx.doi.org/10.1002/anie.200502113

[2] M. Molinos, V. Carvalho, D. M. Silva and F. M. Gama, "Development of a Hybrid Dextrin Hydrogel Encapsulating Dextrin Nanogel as Protein Delivery System," Biomacromolecules, Vol. 13, No. 2, 2012, pp. 517-527. http://dx.doi.org/10.1021/bm2015834

[3] G. J. Hickman, A. Rai, D. J. Boocock, R. C. Rees and C. C. Perry, "Fabrication, Characterisation and Performance of Hydrophilic and Superhydrophilic Silica as Cell Culture Surfaces," Journal of Materials Chemistry, Vol. 22, No. 24, 2012, pp. 12141-12148. http://dx.doi.org/10.1039/c2jm31161e

[4] M. R. N. Monton, E. M. Forsberg and J. D. Brennan, "Tailoring Sol-Gel-Derived Silica Materials for Optical Biosensing," Chemistry of Materials, Vol. 24, No. 5, 2012, pp. 796-811. http://dx.doi.org/10.1021/cm202798e

[5] W. Jin and J. D. Brennan, "Properties and Applications of Proteins Encapsulated within Sol-Gel Derived Materials," Analytica Chimica Acta, Vol. 461, No. 1, 2002, pp. 1-36. http://dx.doi.org/10.1016/S0003-2670(02)00229-5

[6] I. Gill, "Bio-Doped Nanocomposite Polymers: Sol-Gel Bioencapsulates," Chemistry of Materials, Vol. 13, No. 10, 2001, pp. 3404-3421. http://dx.doi.org/10.1021/cm0102483

[7] C. P. Liu and S. D. Liu, "Formulation and Characterization of the Microencapsulated Entomopathogenic Fungus Metarhizium anisopliae MA126," Journal of Microencapsulation, Vol. 26, No. 5, 2009, pp. 377-384. http://dx.doi.org/10.1080/02652040802365455

[8] M. Kato, K. Inuzuka, K. Sakai-Kato and T. Toyo'oka, "Monolithic Bioreactor Immobilizing Trypsin for HighThroughput Analysis," Analytical Chemistry, Vol. 77, No. 6, 2005, pp. 1813-1818. http://dx.doi.org/10.1021/ac048388u

[9] S. Murayama, F. Ishizuka, K. Takagi, H. Inoda, A. Sano, T. Santa and M. Kato, "Small Mesh Size Hydrogel for Functional Photocontrol of Encapsulated Enzymes and Small Probe Molecules," Analytical Chemistry, Vol. 84, 
No. 3, 2012, pp. 1374-1379.

http://dx.doi.org/10.1021/ac2023603

[10] D. J. Dickson and R. L. Ely, "Silica Sol-Gel Encapsulation of Cyanobacteria: Lessons for Academic and Applied Research," Applied Microbiology and Biotechnology, Vol. 97, No. 5, 2013, pp. 1809-1819.

http://dx.doi.org/10.1007/s00253-012-4686-8

[11] N. Bhattarai, H. R. Ramay, J. Gunn, F. A. Matsen and M. Zhang, "PEG-Grafted Chitosan as an Injectable Thermosensitive Hydrogel for Sustained Protein Release," Journal of Controlled Release, Vol. 103, No. 3, 2005, pp. 609624. http://dx.doi.org/10.1016/j.jconrel.2004.12.019

[12] L. E. Vera-Avila, E. García-Salgado, M. P. García de Llasera and A. Peña-Alvarez, "Binding Characteristics of Bovine Serum Albumin Encapsulated in Sol-Gel Glasses: An Alternative for Protein Interaction Studies," Analytical Biochemistry, Vol. 373, No. 2, 2008, pp. 272-280. http://dx.doi.org/10.1016/j.ab.2007.08.036

[13] C. D. Tran, D. Ilieva and S. Challa, "Inhomogeneity in Distribution and Conformation of Bovine Serum Albumin in Sol-Gel: A Closer Look with a Near-Infrared Multispectral Imaging Technique," Journal of Sol-Gel Science and Technology, Vol. 32, No. 1-3, 2004, pp. 207-217. http://dx.doi.org/10.1007/s10971-004-5790-8

[14] Y. Gao, A. Heinemann, R. Knott and J. Bartlett, "Encapsulation of Protein in Silica Matrices: Structural Evolution on the Molecular and Nanoscales," Langmuir, Vol. 26, No. 2, 2010, pp. 1239-1246. http://dx.doi.org/10.1021/la9023986

[15] M. Kato, K. Sakai-Kato, N. Matsumoto and T. Toyo'oka, "A Protein-Encapsulation Technique by the Sol-Gel Method for the Preparation of Monolithic Columns for Capillary Electrochromatography," Analytical Chemistry, Vol. 74, No. 8, 2002, pp. 1915-1921. http://dx.doi.org/10.1021/ac0112162

[16] M. Kato, N. Matsumoto, K. Sakai-Kato and T. Toyo'oka, "Investigation of Chromatographic Performances and Binding Characteristics of BSA-Encapsulated Capillary Column Prepared by the Sol-Gel Method," Journal of Pharmaceutical and Biomedical Analysis, Vol. 30, No. 6, 2003, pp. 1845-1850. http://dx.doi.org/10.1016/S0731-7085(02)00527-7

[17] M. Kato, H. Saruwatari, K. Sakai-Kato and T. Toyo'oka, "Silica Sol-Gel/Organic Hybrid Material for Protein Encapsulated Column of Capillary Electrochromatography," Journal of Chromatography A, Vol. 1044, No. 1-2, 2004, pp. 267-270.

http://dx.doi.org/10.1016/j.chroma.2004.04.056

[18] M. Fujiwara, K. Shiokawa and T. Kubota, "Direct Encapsulation of Proteins into Calcium Silicate Microparticles by Water/Oil/Water Interfacial Reaction Method and Their Responsive Release Behaviors," Materials Science and Engineering C, Vol. 32, No. 8, 2012, pp. 2484-2490. http://dx.doi.org/10.1016/j.msec.2012.07.030

[19] X. Y. Zhao, Y. J. Zhu, F. Chen and J. Wu, "Calcium Phosphate Nanocarriers Dual-Loaded with Bovine Serum Albumin and Ibuprofen: Facile Synthesis, Sequential Drug Loading and Sustained Drug Release," Chemistry-An Asian Journal, Vol. 7, No. 7, 2012, pp. 1610-1615. http://dx.doi.org/10.1002/asia.201100954
[20] M. Igartua, R. M. Hernández, A. Esquisabel, A. R. Gascón, M. B. Calvo and J. L. Pedraz, "Stability of BSA Encapsulated into PLGA Microspheres Using PAGE and Capillary Electrophoresis," International Journal of Pharmaceutics, Vol. 169, No. 1, 1998, pp. 45-54. http://dx.doi.org/10.1016/S0378-5173(98)00101-X

[21] D. H. Chen, D. L. Cole and G. S. Srivatsa, "Determination of Free and Encapsulated Oligonucleotides in Liposome Formulated Drug Product," Journal of Pharmaceutical and Biomedical Analysis, Vol. 22, No. 5, 2000, pp. 791-801. http://dx.doi.org/10.1016/S0731-7085(00)00243-0

[22] Tam. T. T. N. Nguyen, J. Østergaard, S. Stürup and B. Gammelgaard, "Investigation of a Liposomal Oxaliplatin Drug Formulation by Capillary Electrophoresis Hyphenated to Inductively Coupled Plasma Mass Spectrometry (CE-ICP-MS)," Analytical and Bioanalytical Chemistry, Vol. 402, No. 6, 2012, pp. 2131-2139.

http://dx.doi.org/10.1007/s00216-011-5651-6

[23] Tam. T. T. N. Nguyen, J. Østergaard, S. Stürup and B. Gammelgaard, "Metallomics in Drug Development: Characterization of a Liposomal Cisplatin Drug Formulation in Human Plasma by CE-ICP-MS," Analytical and Bioanalytical Chemistry, Vol. 405, No. 6, 2013, pp. 18451854. http://dx.doi.org/10.1007/s00216-012-6355-2

[24] K. J. Wiechelman, R. D. Braun and J. D. Fitzpatrick, "Investigation of the Bicinchoninic Acid Protein Assay: Identification of the Groups Responsible for Color Formation," Analytical Biochemistry, Vol. 175, No. 1, 1988, pp. 231-237. http://dx.doi.org/10.1016/0003-2697(88)90383-1

[25] C. J. Brinker and G. W. Scherer, "Sol-Gel Science: The Physics and Chemistry of Sol-Gel Processing," San Diego, CA, 1990.

[26] J. J. Babcock and L. Brancaleon, "Bovine Serum Albumin Oligomers in the E-and B-Forms at Low Protein Concentration and Ionic Strength," International Journal of Biological Macromolecules, Vol. 53, 2013, pp. 42-53. http://dx.doi.org/10.1016/i.ijbiomac.2012.10.030

[27] M. Dockal, D. C. Carter and F. Ruecker, "Conformational Transitions of the Three Recombinant Domains of Human Serum Albumin Depending on $\mathrm{pH}$," The Journal of Biological Chemistry, Vol. 275, No. 5, 2000, pp. 30423050. http://dx.doi.org/10.1074/jbc.275.5.3042

[28] Y. F. Yan, D. Seeman, B. Q. Zheng, E. Kizilay, Y. S. Xu, and P. L. Dubin, "pH-Dependent Aggregation and Disaggregation of Native $\beta$-Lactoglobulin in Low Salt," Langmuir, Vol. 29, No. 14, 2013, pp. 4584-4593. http://dx.doi.org/10.1021/la400258r

[29] X. J. Gao, X. G. Zhang, X. J. Zhang, C. Cheng, Z. Wang and C. X. Li, "Encapsulation of BSA in Polylactic AcidHyperbranched Polyglycerol Conjugate Nanoparticles: Preparation, Characterization, and Release Kinetics," Polymer Bulletin, Vol. 65, No. 8, 2010, pp. 787-805. http://dx.doi.org/10.1007/s00289-010-0273-2

[30] R. Viitala, M. Jokinen and J. B. Rosenholm, "Mechanistic Studies on Release of Large and Small Molecules from Biodegradable $\mathrm{SiO}_{2}$," International Journal of Pharmaceutics, Vol. 336, No. 2, 2007, pp. 382-390. http://dx.doi.org/10.1016/j.ijpharm.2006.12.008 
[31] C. Qi, Y. J. Zhu, B. Q. Lu, X. Y. Zhao, J. Zhao and F. Chen, "Hydroxyapatite Nanosheet-Assembled Porous Hollow Microspheres: DNA-Templated Hydrothermal Synthesis, Drug Delivery and Protein Adsorption," Journal of Materials Chemistry, Vol. 22, No. 42, 2012, pp. 2264222650. http://dx.doi.org/10.1039/C2JM35280J
[32] M. Ahmed and R. Narain, "Intracellular Delivery of DNA and Enzyme in Active Form using Degradable Carbohydrate-Based Nanogels," Molecular Pharmaceutics, Vol. 9, No. 11, 2012, pp. 3160-3170.

http://dx.doi.org/10.1021/mp300255p 